\title{
Isolation and Antibiotic Susceptibility of the Microorganisms Isolated from Diabetic Foot Infections in Nemazee Hospital, Southern Iran
}

\author{
Mojtaba Anvarinejad, ${ }^{1}$ Gholamreza Pouladfar, ${ }^{1}$ Aziz Japoni, ${ }^{1}$ Shahram Bolandparvaz, ${ }^{2}$ \\ Zeinab Satiary, ${ }^{3}$ Pejman Abbasi, ${ }^{1}$ and Jalal Mardaneh ${ }^{4}$ \\ ${ }^{1}$ Professor Alborzi Clinical Microbiology Research Center, Shiraz University of Medical Sciences, Shiraz, Iran \\ ${ }^{2}$ Trauma Research Center, Shiraz University of Medical Sciences, Shiraz, Iran \\ ${ }^{3}$ General Surgery Ward, Nemazee Hospital, Shiraz University of Medical Sciences, Shiraz, Iran \\ ${ }^{4}$ Department of Microbiology, School of Medicine, Gonabad University of Medical Sciences, Gonabad, Iran \\ Correspondence should be addressed to Jalal Mardaneh; jalalmardaneh@yahoo.com
}

Received 20 September 2015; Revised 16 November 2015; Accepted 29 November 2015

Academic Editor: Giuseppe Comi

Copyright (C) 2015 Mojtaba Anvarinejad et al. This is an open access article distributed under the Creative Commons Attribution License, which permits unrestricted use, distribution, and reproduction in any medium, provided the original work is properly cited.

\begin{abstract}
Background. Diabetic foot infections (DFIs) are a major public health issue and identification of the microorganisms causing such polymicrobial infections is useful to find out appropriate antibiotic therapy. Meanwhile, many reports have shown antibiotic resistance rising dramatically. In the present study, we sought to determine the prevalence of microorganisms detected on culture in complicated DFIs in hospitalized patients and their antibiotic sensitivity profiles. Methods. A cross-sectional study was conducted for a period of 24 months from 2012 to 2014 in Nemazee Hospital, Shiraz, Iran. The demographic and clinical features of the patients were obtained. Antimicrobial susceptibility testing to different agents was carried out using the disc diffusion method. Results. During this period, 122 aerobic microorganisms were isolated from DFIs. Among Gram-positive and Gram-negative bacteria, Staphylococcus spp. and E. coli were the most frequent organisms isolated, respectively. Of the isolates, $91 \%$ were multidrug while $78 \%$ of $S$. aureus isolates were methicillin resistant. 53\% of Gram-negative bacteria were positive for extended-spectrum $\beta$-lactamase. Conclusion. Given the involvement of different microorganisms and emergence of multidrug resistant strains, clinicians are advised to consider culture before initiation of empirical therapy.
\end{abstract}

\section{Introduction}

Diabetic foot is one of the serious complications associated with diabetes and affects quality of life in respective patients in all ages and races [1]. The World Health Organization (WHO) reported increasing incidence of diabetes all around the world, especially in developing countries. The prevalence of diabetes is on the rise in Iran, chiefly in the southern parts $[2,3]$.

Neuropathy, peripheral arterial disease, and pressure overload make the sufferers prone to ulcer. It is estimated that approximately $15-25 \%$ of diabetic patients develop diabetic foot ulcers during the course of the disease. People with diabetes can progress into chronic ulcers often leading to amputation if not treated promptly [4-6]. Age, male gender, and long duration of diabetes are the other factors associated with amputation $[4,7]$.

Chronic wounds can be colonized on the surface by a wide range of organisms [8]. Several studies have shown different bacterial agents isolated from patients in different geographical areas in Iran $[2,9,10]$. The inconsistency in reports might be attributed to the varying research methods and populations. If bacterial infection is mild, it is usually monobacterial and if severe infection is present, it is polymicrobial [9]. The antibiotic susceptibility patterns also show variations in diverse geographical regions [11-13].

Multidrug resistant (MDR) bacteria, methicillin resistant $S$. aureus (MRSA), and extended-spectrum $\beta$-lactamase 
(ESBL) producing Gram-negative bacteria and their associated complications have created a big health concern among the medical and clinical practitioners $[9,14,15]$. In recent decade, high rates of MDR bacteria, MRSA, and ESBL positive strains have been observed in many hospitalized diabetic foot patients (DFP) $[6,9,16]$. Such conditions make the treatment more demanding and many even menacing to the respective hospitalized patients' lives.

Therefore, early diagnosis of lesions and prompt initiation of appropriate antimicrobial therapy are essential for controlling the infection and preventing complication and improving the quality of life. Antibiotic susceptibility test is a requirement for the management of infections which can help to make better therapeutic choices. Hence, this study was designed to evaluate the prevalence of microorganisms in infected diabetic foot cases and their sensitivity patterns in public hospital, in Fars, Shiraz, Southern Iran.

\section{Materials and Methods}

2.1. Patients. This cross-sectional study was carried out on 86 patients admitted with infected diabetic foot. The study design and methodology were approved by the Ethics Committee of Professor Alborzi Clinical Microbiology Research Center and patients' consents were also obtained.

We evaluated the data over a 24 -month period from July 2011 to June 2012.

The study population was defined as the total number of patients with Type 1 Diabetes Mellitus (DM) and Type 2 DM with foot ulcers at initial visit and admission to Nemazee Hospital. Information regarding patients' demographic and clinical features such as age, sex, patients' weights, type of diabetes, wound size, random blood sugar level, nature of ulcer based on Wagner classification, and amputation was gathered. Data related to clinical findings such as neuropathy, vasculopathy, nephropathy, hypertension, and retinopathy were also collected.

The vascular disease and neuropathy patients were firstly assessed based on characterization and position of ulcers and their history and then determined with additional tests. For arterial disease, absence of peripheral pulses, presence of claudication, and CT angiography were performed. For neuropathy, nerve dysfunction, significant painful symptoms, reflex test, and light touch sensory were evaluated. Osteomyelitis was diagnosed on suggestive changes in the radiographs and imaging studies.

Diabetes Mellitus was defined according to the criteria set by the WHO [5].

2.2. Bacterial Isolation. Two specimens (pus, wound exudates) for microbiological studies were obtained from the infected sites. In fact, the clinical signs of infection and also condition of patients make us use swab culture. For ulcer, the wound before sampling was debrided with a sterile scalpel and rinsed with sterile normal saline and then, samples were collected using sterile swabs, from the depth of the wounds to check for the presence of infective agents (deep swab technique). The swabs were transferred into sterile tubes with brain-heart infusion broth. The tubes were immediately transported to the microbiology laboratory. One swab also was used for Gram staining. The isolates were identified by standard methods. The mold species were identified on the basis of their microscopic and macroscopic appearance.

2.3. Antibiotic Susceptibility Patterns. Susceptibility of all the isolates to different antibiotics was determined by the disc diffusion methods, as recommended by the Clinical and Laboratory Standard Institute, using commercial antimicrobial discs (Mast. Co., UK). E. coli ATCC 25922 was used for quality control purposes.

MRSA was determined by using the $30 \mu \mathrm{g}$ cefoxitin disk and oxacillin agar screen plate: the oxacillin (MRSA) agar screen plate was developed for the detection of methicillin resistance in S. aureus. Ten microliters of the $10^{6} \mathrm{CFU} / \mathrm{mL}$ bacterial suspension (final concentration $=10^{4} \mathrm{CFU} / \mathrm{mL}$ ) was inoculated onto MHA plates containing $4 \% \mathrm{NaCl}$ and $6 \mu \mathrm{g} / \mathrm{mL}$ of oxacillin. Any growth occurring within $48 \mathrm{~h}$ incubation at $33-35^{\circ} \mathrm{C}$ was taken to be oxacillin resistant. All Enterococcus isolates were examined for reduced vancomycin susceptibility by agar incorporation. ESBL detection for Gramnegative bacilli was done using combined disk method ceftazidime $(30 \mu \mathrm{g})$, ceftazidime/clavulanic acid $(30 \mu \mathrm{g} / 10 \mu \mathrm{g})$, and cefotaxime $(30 \mu \mathrm{g})$ and cefotaxime/clavulanic acid $(30 \mu \mathrm{g} / 10 \mu \mathrm{g})$.

All computations for statistical analysis were done by SPSS ver. 19 (IBM, USA).

\section{Results}

3.1. Patients' Data. Eighty-six patients with a mean age of 55.5 years hospitalized in surgery wards were studied during the abovementioned period. They included 56 males (65\%) and 30 females (35\%). The mean duration of diabetes was 13.5 years. DFP weights ranged from 43 to $100 \mathrm{~kg}$, of which 28 cases were over $75 \mathrm{~kg}$ (32\%). Mean random blood sugar level was $288.5 \mathrm{mg} / \mathrm{dL}$. Median ulcer duration at initial visit was 15 days (range 1-120). Seventy-four (86\%) patients received antibiotic treatment on admission (3 patients: cefalexin, 6 patients: imipenem and vancomycin, and 65 patients: clindamycin and ciprofloxacin). Ciprofloxacin $400 \mathrm{mg}$ IV twice a day and clindamycin $900 \mathrm{mg}$ IV three times a day were administered.

Table 1 shows the nature of ulcer and other clinical data. Information about types of ulcers was collected according to the Wagner ulcer classification system. All patients had ulcers graded as $0-4$ in the Wagner classification with grade 3 as the most prevalent. Totally, 18 patients presented with osteomyelitis and were diagnosed based on history, physical examination findings, and radiographic and other imaging studies. There were $26(30 \%)$ patients with peripheral arterial disease diagnosed as ischemic ulcer on the day of admission.

\subsection{Bacterial Isolates and Antibiotic Susceptibility Patterns.} Totally, 122 aerobic microorganisms were isolated from the patients. Among them, 78 were Gram-positive, 7 were fungi, and others were Gram-negative. 
TABLE 1: Demographic and clinical data of diabetic foot patients.

\begin{tabular}{lcc}
\hline Parameter & Values & [Range or $n(\%)]$ \\
\hline $\begin{array}{l}\text { Mean duration of } \\
\text { diabetes (years) }\end{array}$ & & 13.5 \\
\hline Wound size & $\leq 4 \mathrm{~mm}$ & $22(25)$ \\
& $\geq 4 \mathrm{~mm}$ & $64(75)$ \\
Weight range & $\leq 50 \mathrm{kgs}$ & $4(5)$ \\
& $50-75$ & $54(63)$ \\
& $\geq 75$ & $28(32)$ \\
\hline Diabetic type & Type 1 & $45(52)$ \\
\hline Amputation & Type 2 & $41(48)$ \\
\hline & & $42(49)$ \\
Wagner grading of ulcer & I & $9(11)$ \\
& II & $17(20)$ \\
& III & $15(17)$ \\
& IV & $31(36)$ \\
& Vascular diseases & $48(56)$ \\
Complication & Hypertension & $32(37)$ \\
& Neuropathy & $22(25)$ \\
& Nephropathy & $14(16)$ \\
& Retinopathy & $10(11)$ \\
\hline
\end{tabular}

The most common isolated bacteria were Staphylococcus spp. (29\%), Enterococcus spp. (27\%), and E. coli (20\%). The count and percent of the organisms are presented in Table 2.

According to the in vitro antibiotic susceptibility testing, linezolid was the most effective antibiotic against Enterococcus isolates (all isolates (100\%) were sensitive) and ciprofloxacin was the least effective antimicrobial (all isolates (100\%) were resistant). As revealed, 20.6\% of the Enterococcus were resistant to vancomycin. As for Staphylococcus spp., linezolid and vancomycin were the most effective antibiotics. $78 \%$ of these isolates were MRSA. Resistance rates for $S$. aureus were presented in Figure 1. All Gram-negative bacteria were sensitive to colistin and polymyxin B and $53 \%$ of Gramnegative bacteria were ESBL positive. Resistance rates for Enterobacteriaceae and nonfermenters were presented in Table 3 and Figure 2, respectively.

Among 81 bacterial isolates for which we performed antibiotic test, $91 \%$ were multidrug resistant; that is, they were resistant to 3 or more antibiotics and considered as MDR [17].

\section{Discussion}

Foot ulceration is the most severe complication affecting diabetic patients which is not confined to certain superficial underlying subcutaneous tissue. Diabetic foot ulceration (DFU) arises from uncontrolled diabetes and incomplete health self-care $[18,19]$. This study investigates clinical and microbiological findings of DFU in patients. The majority of the patients with DFU were male and older than 40 years, consistent with other reported studies $[7,20]$. This may be due
TABLE 2: Frequency of organisms isolated from diabetic foot patients.

\begin{tabular}{lc}
\hline Organism & Frequency N (\%) \\
\hline Enterococcus spp. & $34(27)$ \\
Staphylococcus: CONs & $28(22)$ \\
E. coli & $25(20)$ \\
Staphylococcus: COPs & $9(7)$ \\
Bacillus & $4(3)$ \\
Candida albicans & $3(3)$ \\
Proteus spp. & $3(3)$ \\
Diphtheroid spp. & $2(2)$ \\
Pseudomonas aeruginosa & $2(2)$ \\
Candida spp. & $1(1)$ \\
Klebsiella pneumoniae & $1(1)$ \\
Beta hemolytic strep. g. A & $1(1)$ \\
Serratia liquefaciens & $1(1)$ \\
Acinetobacter baumannii & $1(1)$ \\
Acinetobacter lwoffi & $1(1)$ \\
Enterobacter gergoviae & $1(1)$ \\
Morganella morganii & $1(1)$ \\
S. maltophilia & $1(1)$ \\
Fungi & $3(3)$ \\
Totally & 122 \\
\hline
\end{tabular}

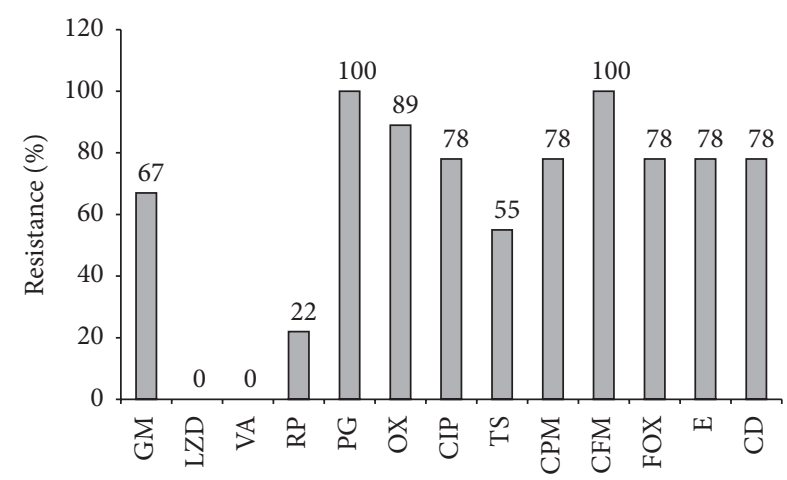

$\begin{array}{ll}\text { GM: gentamycin } & \text { TS: cotrimoxazol } \\ \text { LZD: linezolid } & \text { CPM: cefepime } \\ \text { VA: vancomycin } & \text { CFM: cefexim } \\ \text { RP: rifampicin } & \text { FOX: cefoxitin } \\ \text { PG: penicillin G } & \text { E: erytromycin } \\ \text { OX: oxacillin } & \text { CD: clindamycin } \\ \text { CIP: ciprofloxacin } & \end{array}$

FIGURE 1: Antibiotic resistance patterns of $S$. aureus isolated from diabetic foot patients.

to factors such as the differences in life styles and professional activities and jobs, causing the feet to tolerate more pressure.

In the present study, vascular diseases were the main risk factor among the patients, which is also noted in other studies [21-23]. The percentage of patients involved with neuropathy is comparable to other studies in Iran $[24,25]$. Of course, the prevalence varies in different studies, which could be explained by different sample sizes, different distributions of 
TABLE 3: Antibiotic resistance patterns of Enterobacteriaceae (32) strains isolated from diabetic foot patients.

\begin{tabular}{lc}
\hline Antibiotic & Total resistant strains $N(\%)$ \\
\hline Tetracycline & $29(90)$ \\
Ampicillin & $27(84)$ \\
Trimethoprim-sulfamethoxazole & $25(78)$ \\
Ciprofloxacin & $25(78)$ \\
Amoxicillin clavulanic acid & $21(65)$ \\
Cefalexin & $21(65)$ \\
Cefotaxime & $18(56)$ \\
Chloramphenicol & $18(56)$ \\
Tobramycin & $18(56)$ \\
Aztreonam & $17(53)$ \\
Ceftriaxone & $17(53)$ \\
Ceftazidime & $16(50)$ \\
Cefepime & $15(47)$ \\
Piperacillin tazobactam & $13(40)$ \\
Gentamicin & $13(40)$ \\
Meropenem & $3(9)$ \\
Amikacin & $2(6)$ \\
Imipenem & $1(3)$ \\
Polymyxin B, colistin & $0(0)$ \\
\hline
\end{tabular}

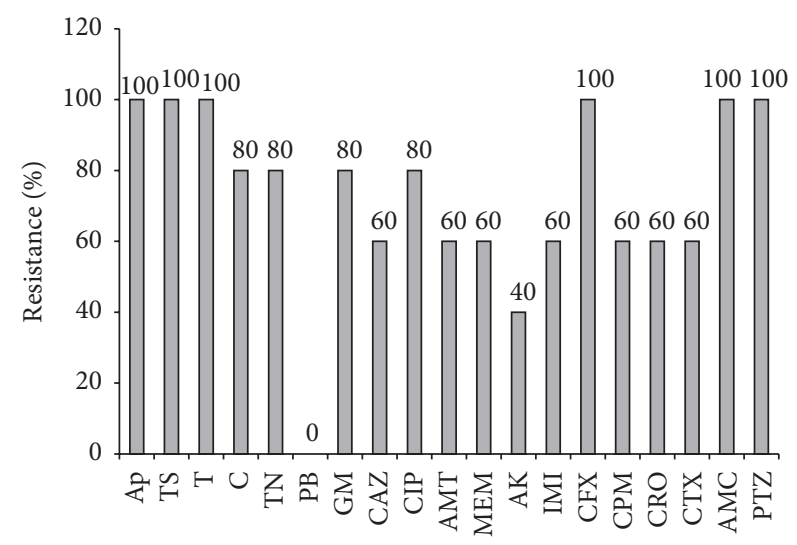

$\begin{array}{ll}\text { AP: ampicillin } & \text { MEM: meropenem } \\ \text { TS: cotrimoxazol } & \text { AK: amikacin } \\ \text { T: tetracyclin } & \text { IMI: imipenem } \\ \text { C: chloramphenicol } & \text { CFX: cefalexin } \\ \text { TN: tobramycin } & \text { CPM: cefepime } \\ \text { PB: polymixin B } & \text { CRO: ceftriaxone } \\ \text { GM: gentamicin } & \text { CTX: cefotaxim } \\ \text { CAZ: ceftazidim } & \text { AMC: augmentin } \\ \text { CIP: ciprofloxacin } & \text { PTZ: piperacillin tazobactam } \\ \text { ATM: aztronam } & \end{array}$

FIGURE 2: Antibiotic resistance patterns of nonfermenter Gramnegative strains isolated from diabetic foot patients.

risk factors, and also habits and life styles of the patients such as eating habits and physical activities that can increase the prevalence of risk factors.

The validity and accuracy of using swab versus biopsy culture were addressed in some studies. Some have found that tissue specimens are more sensitive and specific than swab cultures $[26,27]$ while others have reported that, with debridement, the use of a wound swab, as the most common technique, is as reliable as the use of a tissue specimen, at least for initial monitoring [28-31]. Taking into account the study limitations including the lack of easy access to biopsy samples, clinical signs of infections, and patients' conditions, we were encouraged to use deep swab culture.

In the present study, 79 percent of cases had monomicrobial infection, similar to other studies [32-34], but Lipsky reported in 2012 that polymicrobial strains were most common [35]. The point to be noted here is that we did not consider anaerobic bacteria and monobacterial infections were found to be more prevalent.

We collected 78 Gram-positive bacteria, as in previous studies which reported that Gram-positive strains were more isolated from DFP [9, 10, 34]. In contrast, Gadepalli et al. found that Gram-negative bacteria (Proteus species, E. coli, and Pseudomonas aeruginosa) were predominant strains [6]. Source of infection, use of antibiotic drug for treatment, sample collection method, geographical variation, and type and severity of the infections can influence the pathogens diversity in different geographical areas including Iran. We found that Staphylococcus spp. (28 CONs, 9 COPs) were the most frequent pathogens isolated from the patients, as stated in the majority of studies [13, 36]. Enterococcus spp. were the second most frequent microorganisms which might be due to previous usage of antibiotics. The increased prevalence of Enterococci has emerged as a public health concern. Enterococci are frequently detected in compromised patients, such as diabetics, and in their foot ulcers, but their role in infections at these sites is not clearly defined [37].

Gram-negative bacilli and mixed infection were more evident in grades 3 and 4 whereas Gram-positive cocci were most common in grades 1 and 2, indicating that Gram-negative infections increase the severity and make the patients prone to amputation. As revealed, 42 patients underwent amputation, in 32 cases of which Gram-negative bacteria were detected.

Fungal infection was observed in $6 \%$ of the patients. In the present study, we isolated $3 \mathrm{C}$. albicans, 1 Candida genus, and 3 Aspergillus spp. (2 A. niger, 1 A. flavus) from cases of DFI. Some studies have noted high prevalence of Candida spp. [38, 39], whereas others reported opportunistic molds species as the causative agents of fungal infections in the DFP $[38,40]$. Most of the patients involved with fungal infections were in Wagner grades 3 and 4 . It is worth mentioning that the patients in our study with diabetic foot ulcers did not receive any antifungal agents at all. So DFP should be examined for fungal infections and also evaluated mycologically for ulcers.

Nowadays, a big concern among the medical and clinical practitioners is the emerging MDR organisms and their associated complications in developing countries [41, 42]. In the current study, ninety-one percent of the bacteria were resistant to three or more antibiotics. Multidrug resistance rates of isolates in 2014 were $63.4 \%$, while the reported rate in 2004 was $18 \%$ [43, 44]. To alleviate the rate of MDR and spread of resistance, clinicians should switch to narrowerspectrum therapy. 
All the isolates were tested for their antibiotic resistance. The resistance patterns for Enterobacteriaceae, nonfermenters, and $S$. aureus are presented in Table 1 and Figures 1 and 2. The Enterobacteriaceae family was resistant to the majority of antibiotics tested, except colistin, imipenem, amikacin, and meropenem, partially consistent with the results of other studies [11, 45]. But among nonfermenter Gram-negative bacteria, only colistin and polymyxin B were completely sensitive where $60 \%$ of strains were resistant to imipenem and meropenem. As for Staphylococcus spp., linezolid and vancomycin were the most effective antibiotics and low resistance was seen to rifampicin but a high resistance exhibited to other antibiotics. Other studies have shown different susceptibility antibiotic patterns and approximately in most, vancomycin and linezolid have shown good activity against the strains $[9,46,47]$.

The high rates of antibiotic resistance shown in the present study may be due to such factors including hospitalization, recent use of broad-spectrum antibiotics, history of surgery and chronic wounds, irrational use of antibiotics, and the transfer of resistance genes by transport means.

High level of resistance to ciprofloxacin and clindamycin was seen among all the isolates. These antibiotics were used for almost all the patients as empirical therapy in our study. However, it should be noted that clindamycin is also used for anaerobic organisms but we did not examine such organisms in this study. In a study conducted in 2014, it was shown that combination use of these antibiotics does not lead to the desired result [48]. In addition, high rate of resistance to ciprofloxacin was noted by other studies [34, 49].

Although we can not specify an appropriate treatment regimen, considering the results it can be suggested that the best agents for Enterobacteriaceae isolates are polymyxin B, colistin, carbapenem, and amikacin. Polymyxin B and colistin also seem to be the best antibiotics for nonfermenter strains. For Gram-positive cocci, low rate resistance to linezolid and vancomycin was revealed. This could be explained by low prescription of such antibacterial agents for infections in the patients. It seems that these antibiotics can serve as drugs of choice for the treatment of DFI in the abovementioned hospital. On the other hand, consumption of some drugs is limited according to the patients clinical status [36].

As for the alarming types of resistance (i.e., vancomycin resistant enterococci, MRSA, and ESBL), our data showed that the percentages of VRE, MRSA, and ESBL were 20.6\%, $78 \%$, and $53 \%$, respectively. These rates are comparable with those in other studies from Iran $[9,13,50]$. Infections with these isolates are more difficult to treat than ordinary ones, because the strains do not respond well to many common antibiotics used to kill bacteria.

To alleviate this situation and also reduce the rate of amputation, clinicians should prescribe antibiotics rationally, timely, and sufficiently and there should be periodic supervisions on the drug consumption by the respective organizations [14].

\section{Conclusion}

It can be concluded that culture specimens for correct management of the DFI and knowledge of the susceptibility of antimicrobial drugs are essential for the choice of appropriate antibiotics with maximum efficacy.

\section{Conflict of Interests}

The authors declare no conflict of interests.

\section{Acknowledgments}

This work was supported by a research grant from Professor Alborzi Clinical Microbiology Research Center. The authors' deep gratitude is due to Hassan Khajehei, Ph.D., for linguistic copyediting.

\section{References}

[1] A. A. Kiadaliri, B. Najafi, and M. Mirmalek-Sani, "Quality of life in people with diabetes: a systematic review of studies in Iran," Journal of Diabetes and Metabolic Disorders, vol. 12, no. 1, article 54, 2013.

[2] A. Hadadi, H. Omdeh Ghiasi, M. Hajabdolbaghi, M. Zandekarimi, and R. Hamidian, "Diabetic Foot: infections and outcomes in Iranian admitted patients," Jundishapur Journal of Microbiology, vol. 7, no. 7, Article ID el1680, 2014.

[3] B. Larijani and S. H. Ranjbar, "Overview of diabetic foot; novel treatments in diabetic foot ulcer," DARU, vol. 16, supplement 1 , pp. 1-6, 2008.

[4] S. H. Won, C. Y. Chung, M. S. Park et al., "Risk factors associated with amputation-free survival in patient with diabetic foot ulcers," Yonsei Medical Journal, vol. 55, no. 5, pp. 1373-1378, 2014.

[5] N. Haji Zaine, J. Burns, M. Vicaretti, J. P. Fletcher, L. Begg, and K. Hitos, "Characteristics of diabetic foot ulcers in Western Sydney, Australia," Journal of Foot and Ankle Research, vol. 7, no. 1, article 39, 2014.

[6] R. Gadepalli, B. Dhawan, V. Sreenivas, A. Kapil, A. C. Ammini, and R. Chaudhry, "A clinico-microbiological study of diabetic foot ulcers in an Indian tertiary care hospital," Diabetes Care, vol. 29, no. 8, pp. 1727-1732, 2006.

[7] B. Deribe, K. Woldemichael, and G. Nemera, "Prevalence and factors influencing diabetic foot ulcer among diabetic patients attending arbaminch hospital, south ethiopia," Research, vol. 2, no. 322, article 2, 2014.

[8] G. T. Matsuura and N. Barg, "Update on the antimicrobial management of foot infections in patients with diabetes," Clinical Diabetes, vol. 31, no. 2, pp. 59-65, 2013.

[9] M. T. Akhi, R. Ghotaslou, M. Asgharzadeh et al., "Bacterial etiology and antibiotic susceptibility pattern of diabetic foot infections in Tabriz, Iran," GMS Hygiene and Infection Control, vol. 10, 2015.

[10] A. Dezfulian, M. Salehian, V. Amini et al., "Bacteriological study of diabetic foot infections in an Iranian hospital," Iranian Red Crescent Medical Journal, vol. 13, no. 8, pp. 590-591, 2011.

[11] T. Mathangi and P. Prabhakaran, "Prevalence of bacteria isolated from type 2 diabetic foot ulcers and the antibiotic susceptibility pattern," International Journal of Current Microbiology and Applied Sciences, vol. 2, no. 10, pp. 329-337, 2013. 
[12] V. Turhan, M. Mutluoglu, A. Acar et al., "Increasing incidence of Gram-negative organisms in bacterial agents isolated from diabetic foot ulcers," The Journal of Infection in Developing Countries, vol. 7, no. 10, pp. 707-712, 2013.

[13] M. Amini, A. Davati, and M. Piri, "Determination of the resistance pattern of prevalent aerobic bacterial infections of diabetic foot ulcer," Iranian Journal of Pathology, vol. 8, no. 1, pp. 21-26, 2013.

[14] S. Farshad, M. Anvarinejad, A. M. Tavana et al., "Molecular epidemiology of Escherichia coli strains isolated from children with community acquired urinary tract infections," African Journal of Microbiology Research, vol. 5, no. 26, pp. 4476-4483, 2011.

[15] J. J. Mendes, A. Marques-Costa, C. Vilela et al., "Clinical and bacteriological survey of diabetic foot infections in Lisbon," Diabetes Research and Clinical Practice, vol. 95, no. 1, pp. 153161, 2012.

[16] P. Ramakant, A. K. Verma, R. Misra et al., "Changing microbiological profile of pathogenic bacteria in diabetic foot infections: time for a rethink on which empirical therapy to choose?" Diabetologia, vol. 54, no. 1, pp. 58-64, 2011.

[17] M. Anvarinejad, S. Farshad, A. Alborzi, R. Ranjbar, G. M. Giammanco, and A. Japoni, "Integron and genotype patterns of quinolones-resistant uropathogenic Escherichia coli," African Journal of Microbiology Research, vol. 5, no. 22, pp. 3765-3770, 2011.

[18] J. Mendes and J. Neves, "Diabetic foot infections: current diagnosis and treatment," The Journal of Diabetic Foot Complications, vol. 4, no. 2, pp. 26-45, 2012.

[19] American Diabetes Association, "Standards of medical care in diabetes-2011,” Diabetes Care, vol. 34, supplement 1, pp. S11S61, 2011.

[20] K. Al-Rubeaan, M. Al Derwish, S. Ouizi et al., "Diabetic foot complications and their risk factors from a large retrospective cohort study," PLoS ONE, vol. 10, no. 5, Article ID e0124446, 2015.

[21] K. S. Reid, B. D. Martin, F. Duerksen et al., "Diabetic foot complications in a northern Canadian Aboriginal community," Foot \& Ankle International, vol. 27, no. 12, pp. 1065-1073, 2006.

[22] N. E. Al Kafrawy, E. A. Mustafa, A. E. Dawood, O. Ebaid, and O. M. A. Zidane, "Study of risk factors of diabetic foot ulcers," Menoufia Medical Journal, vol. 27, no. 1, pp. 28-34, 2014.

[23] S. Morbach, H. Furchert, U. Gröblinghoff et al., "Long-term prognosis of diabetic foot patients and their limbs: amputation and death over the course of a decade," Diabetes Care, vol. 35, no. 10, pp. 2021-2027, 2012.

[24] S. Sobhani, H. Asayesh, F. Sharifi et al., "Prevalence of diabetic peripheral neuropathy in Iran: a systematic review and metaanalysis," Journal of Diabetes \& Metabolic Disorders, vol. 13, no. 1, article 97, 2014.

[25] O. G. H. Ranjbar, M. Soveid, H. Rajaii, and A. A. Sadegholvaad, "The incidence of chronic diabetic complications during a 12 years period in patients referring to clinics of Shiraz University of Medical Sciences," Journal of Diabetes and Metabolic Disorders, vol. 3, p. 68, 2004.

[26] J. M. Embil and E. Trepman, "Microbiological evaluation of diabetic foot osteomyelitis," Clinical Infectious Diseases, vol. 42, no. 1, pp. 63-65, 2006.

[27] E. Senneville, H. Melliez, E. Beltrand et al., "Culture of percutaneous bone biopsy specimens for diagnosis of diabetic foot osteomyelitis: concordance with ulcer swab cultures," Clinical Infectious Diseases, vol. 42, no. 1, pp. 57-62, 2006.
[28] R. A. Slater, T. Lazarovitch, I. Boldur et al., "Swab cultures accurately identify bacterial pathogens in diabetic foot wounds not involving bone," Diabetic Medicine, vol. 21, no. 7, pp. 705709, 2004.

[29] F. Bozkurt, S. Gülsün, R. Tekin, S. Hoşoğlu, and H. Acemoğlu, "Comparison of microbiological results of deep tissue biopsy and superficial swab in diabetic foot infections," Journal of Microbiology and Infectious Diseases, vol. 1, no. 3, pp. 122-127, 2011.

[30] E. A. Nelson, S. O’Meara, D. Craig et al., "A series of systematic reviews to inform a decision analysis for sampling and treating infected diabetic foot ulcers," Health Technology Assessment, vol. 10, no. 12, article 238, 2006.

[31] G. Pellizzer, M. Strazzabosco, S. Presi et al., "Deep tissue biopsy vs. superficial swab culture monitoring in the microbiological assessment of limb-threatening diabetic foot infection," Diabetic Medicine, vol. 18, no. 10, pp. 822-827, 2001.

[32] M. Zubair, A. Malik, and J. Ahmad, "Clinico-bacteriology and risk factors for the diabetic foot infection with multidrug resistant microorganisms in north India," Biology and Medicine, vol. 2, no. 4, pp. 22-34, 2010.

[33] S. Tiwari, D. D. Pratyush, A. Dwivedi, S. K. Gupta, M. Rai, and S. K. Singh, "Microbiological and clinical characteristics of diabetic foot infections in northern India," Journal of Infection in Developing Countries, vol. 6, no. 4, pp. 329-332, 2012.

[34] S. J. C. Daniel, E. Gowthami, and S. Sowmiya, "Isolation and identification of bacterial pathogens from wounds of diabetic patients," International Journal of Current Microbiology and Applied Sciences, vol. 2, no. 11, pp. 72-77, 2013.

[35] B. A. Lipsky, A. R. Berendt, P. B. Cornia et al., "2012 Infectious diseases society of America clinical practice guideline for the diagnosis and treatment of diabetic foot infections," Clinical Infectious Diseases, vol. 54, no. 12, pp. el32-e173, 2012.

[36] A. T. El-Tahawy, "Bacteriology of diabetic foot infections," Saudi Medical Journal, vol. 21, no. 4, pp. 344-347, 2000.

[37] N. I. Agudelo Higuita and M. M. Huycke, "Enterococcal disease, epidemiology, and implications for treatment," in Enterococci: From Commensals to Leading Causes of Drug Resistant Infection, M. S. Gilmore, D. B. Clewell, Y. Ike, and N. Shankar, Eds., Massachusetts Eye and Ear Infirmary, Boston, Mass, USA, 2014.

[38] S. Nair, S. Peter, A. Sasidharan, S. Sistla, and A. K. K. Unni, "Incidence of mycotic infections in diabetic foot tissue," Journal of Culture Collections, vol. 5, pp. 85-89, 2006.

[39] E. Bansal, A. Garg, S. Bhatia, A. K. Attri, and J. Chander, "Spectrum of microbial flora in diabetic foot ulcers," Indian Journal of Pathology and Microbiology, vol. 51, no. 2, pp. 204208, 2008.

[40] M. Eckhard, A. Lengler, J. Liersch, R. G. Bretzel, and P. Mayser, "Fungal foot infections in patients with diabetes mellitusresults of two independent investigations," Mycoses, vol. 50, supplement s2, pp. 14-19, 2007.

[41] A. Japoni, A. Vazin, M. Hamedi, M. A. Davarpanah, A. Alborzi, and N. Rafaatpour, "Multidrug-resistant bacteria isolated from intensive-care-unit patient samples," Brazilian Journal of Infectious Diseases, vol. 13, no. 2, pp. 118-122, 2009.

[42] S. Farshad, R. Ranjbar, M. Anvarinejad, M. A. Shahidi, and M. Hosseini, "Emergence of multi drug resistant strains of Eschetichia coli isolated from urinary tract infection," The Open Conference Proceedings Journal, vol. 1, no. 1, pp. 192-196, 2010.

[43] U. Trivedi, S. Parameswaran, A. Armstrong et al., "Prevalence of multiple antibiotic resistant infections in diabetic versus 
nondiabetic wounds," Journal of Pathogens, vol. 2014, Article ID 173053, 6 pages, 2014.

[44] A. Hartemann-Heurtier, J. Robert, S. Jacqueminet et al., "Diabetic foot ulcer and multidrug-resistant organisms: risk factors and impact," Diabetic Medicine, vol. 21, no. 7, pp. 710-715, 2004.

[45] G. Banashankari, H. Rudresh, and A. Harsha, "Prevalence of gram negative bacteria in diabetic foot-a clinicomicrobiological study," Al Ameen Journal of Medical Sciences, vol. 5, no. 3, pp. 224-232, 2012.

[46] A. A.-H. Hefni, A.-M. R. Ibrahim, K. M. Attia et al., "Bacteriological study of diabetic foot infection in Egypt," Journal of the Arab Society for Medical Research, vol. 8, pp. 26-32, 2013.

[47] V. J. Mehta, K. M. Kikani, and S. J. Mehta, "Microbiological profile of diabetic foot ulcers and its antibiotic susceptibility pattern in a teaching hospital, Gujarat," International Journal of Basic \& Clinical Pharmacology, vol. 3, no. 1, pp. 92-95, 2014.

[48] A. F. de Oliveira and H. D. Oliveira Filho, "Microbiological species and antimicrobial resistance profile in patients with diabetic foot infections," Jornal Vascular Brasileiro, vol. 13, no. 4, pp. 289-293, 2014.

[49] G. Siami, N. Christou, I. Eiseman et al., "Clinafloxacin versus piperacillin-tazobactam in treatment of patients with severe skin and soft tissue infections," Antimicrobial Agents and Chemotherapy, vol. 45, no. 2, pp. 525-531, 2001.

[50] N. Rouhipour, A. Hayatshahi, M. K. Nikoo et al., "Clinical microbiology study of diabetic foot ulcer in Iran; pathogens and antibacterial susceptibility," African Journal of Microbiology Research, vol. 6, no. 27, pp. 5601-5608, 2012. 


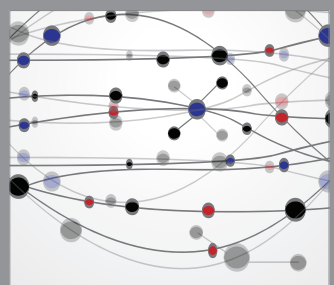

The Scientific World Journal
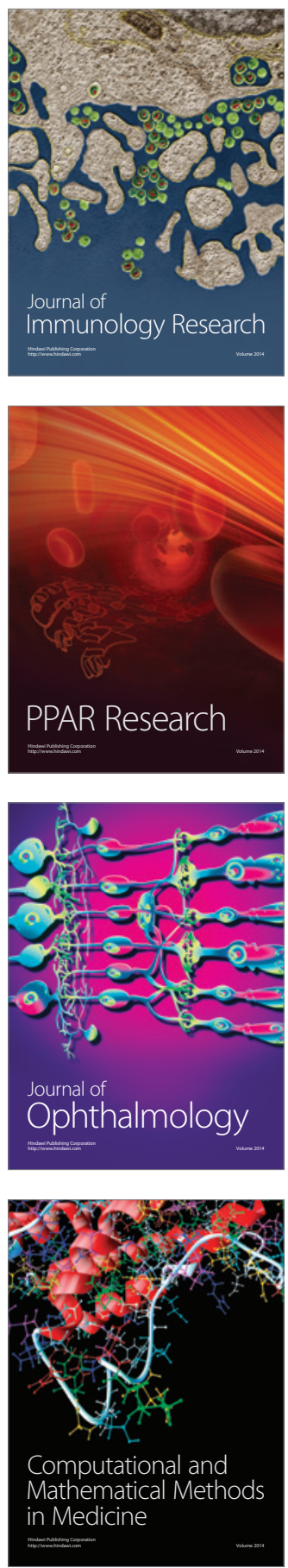

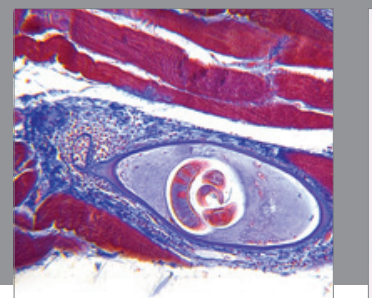

Gastroenterology

Research and Practice
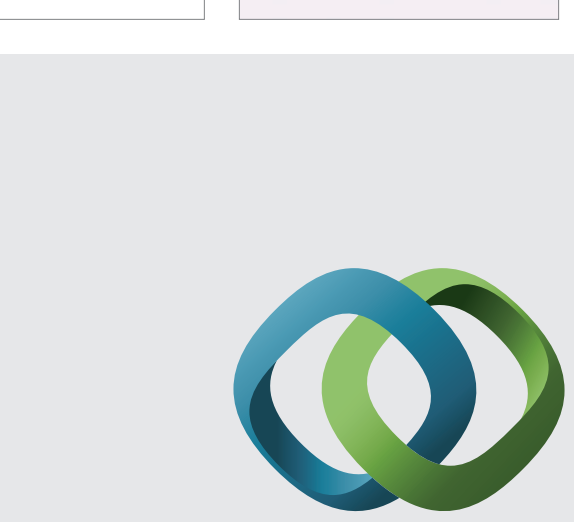

\section{Hindawi}

Submit your manuscripts at

http://www.hindawi.com
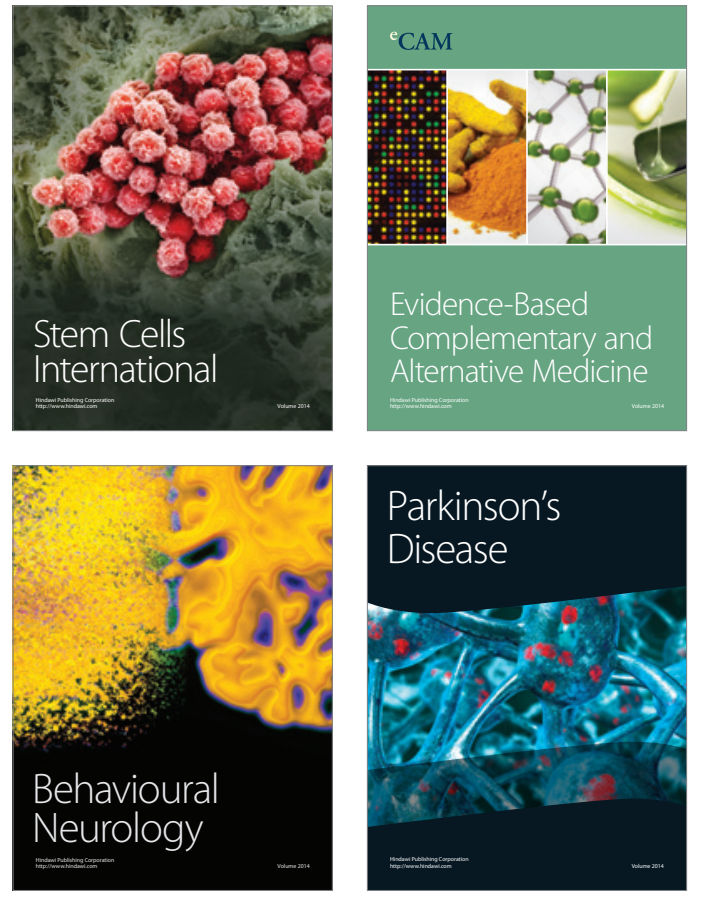
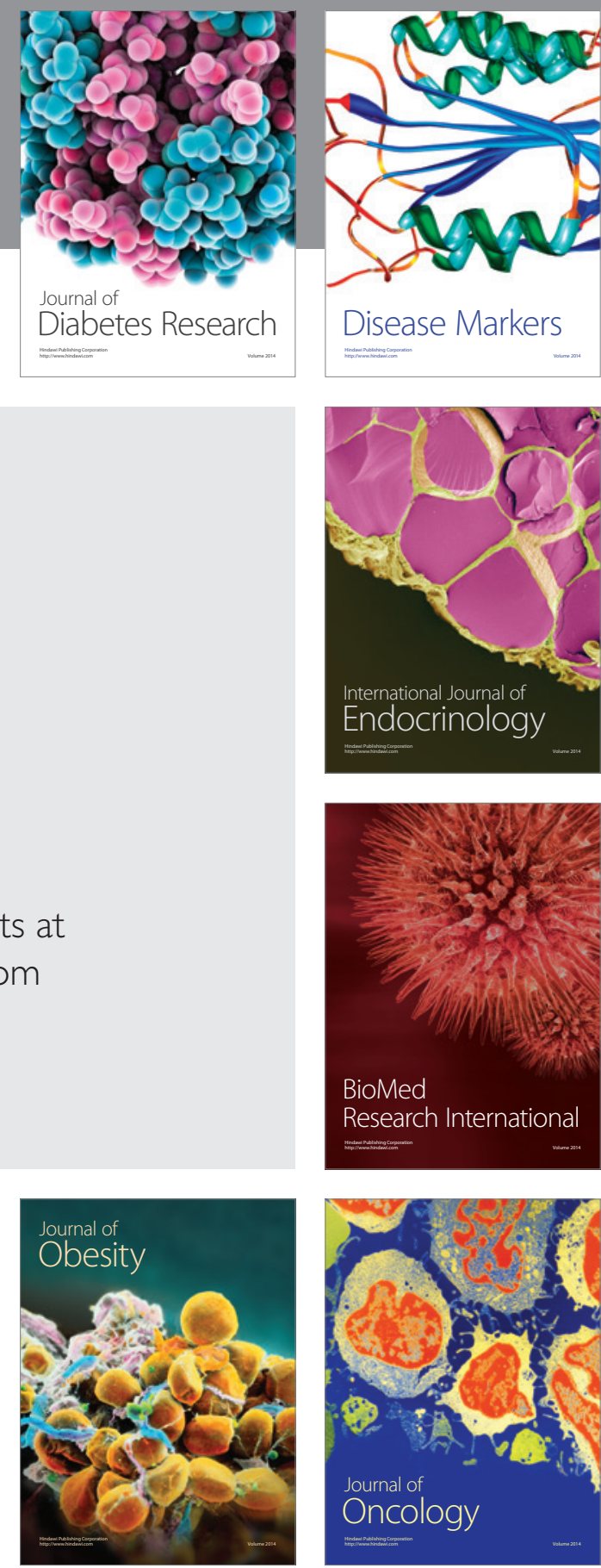

Disease Markers
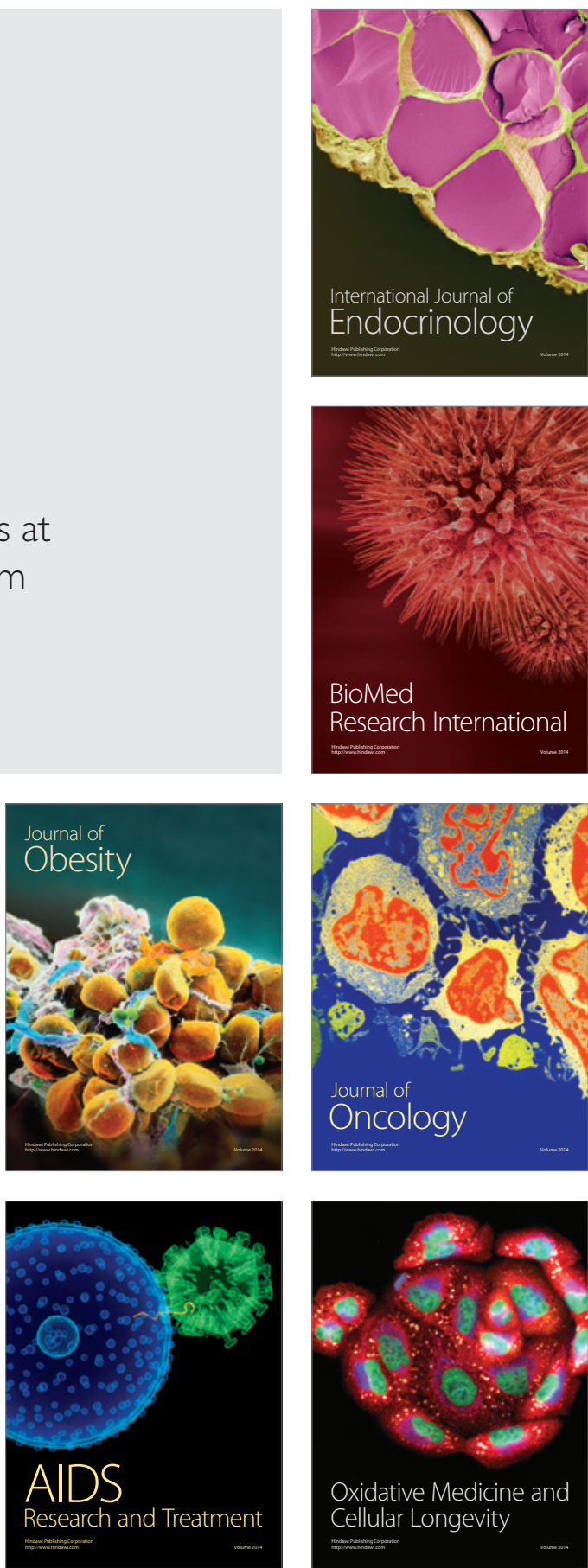